Currently, this may appear to disadvantage UK doctors, who have to undergo longer training than their European counterparts. The Calman Report addressed this issue by proposing improvements to training that will mean that it is shorter and more structured, while not affecting quality standards (Kisely, 1993).

Content of training will remain the prerogative of the competent body in every member state. In the UK this will be the Royal College of Psychiatrists. There is no question of UK trainees having to learn about neurology or la bouffee delirante, unless they wish to.

In addition, there is no reason why the introduction of a unified training grade and shorter training would mean the end of psychiatric subspecialties. In Australia and New Zealand, where training in a unified grade lasts only five years, their college has sections for child psychiatry, alcohol and other drugs, forensic psychiatry, psychiatry of old age, psychotherapy, and social \& cultural psychiatry. If anything, training in Australia is more comprehensive, in that exposure to child and liaison psychiatry is obligatory.

I happen to enjoy research, having just completed one academic job, and starting another later this year, but many trainees wish to concentrate on clinical, teaching or administrative duties. There has been an over-emphasis on the requirement for research in medicine in this country. Experience in research should be available for everyone who is interested, not as a means of filling in time while awaiting a consultant post.

There are very real dangers to training and the speciality with the advent of the changes envisaged by the Calman Report, but not the loss of subspecialities or research opportunities. If the government persists in implementing change without additional funds for greater numbers of consultants, career opportunities may well worsen. Loss of training opportunities, or pay, are far more likely to arise out of the government's reforms of the health service. Additionally, training and pay may be influenced by the opportunities for Trusts to employ doctors without regard to national terms and conditions of service or manpower restrictions.

KisELY, S.R. (1993) The future of psychlatric training after the Calman Report. Psychiatric Bulletin, 17, 610-612.

STEVE KISELY, Northamptonshire Health Authority, Highfield Road, Cliftonville Road, Northampton NN1 5DN

We cannot look into the future. That is the main reason why we have spoken of likely consequences of Euro-harmonisation for psychiatric training (Psychiatric Bulletin, April 1994, 18, 193-195). It is unclear to us how it is possible for Dr Kisely to state that our conclusions do not accord with the facts. Which facts? The process of harmonisation is only in its earliest stages and, as far as we are aware, Calman's recommendations have not been implemented yet in psychiatric training. We suspect that Dr Kisely is creating his own argument, disregarding one of the very few hard facts in this discussion; according to the Calman Report (p. 33), training will have to be shortened by one to three years to a maximum of five to six years. A simple calculation teaches us that, if the duration of subspecialty training were to remain at its present duration (four years), one to two years will be left for general psychiatric training. As this is unlikely to be acceptable we expect that the only option will be to shorten subspecialty training. A similar arithmetic is applicable, mutatis mutandis, to time spent in research. Quod erat demonstradum!

JAN NEELEMAN and JIM VAN Os, The Maudsley Hospital and the Institute of Psychiatry, Denmark Hill, London SE5 8AZ

\section{Ethical dilemmas in drug treatments}

Sir: While the case described by Tyrer and commented upon by Smith \& Adshead (Psychtatric Bulletin, April 1994, 18, 203-204) would appear to represent a commendably flexible interpretation of the doctor/patient contract, I fear that due to other factors, such an approach is increasingly likely to be impractical and for the responsible medical officer, dangerous.

Cold (1994) has summarised the increasingly alarming position in which psychiatrists are being placed in terms of their accountability for the acts of their patients and it seems quite clear that if Tyrer's patient were to behave violently and cause harm to someone, then Tyrer would be held accountable for this and possibly face disciplinary proceedings.

The dilemma, I would suggest, is not so much between professional standards and patients' freedom but now between professional survival and that freedom.

CoID. J. (1994) Failure in community care: psychiatry's dilemma. British Medical Journal. 308, 805-806.

D.R. DAVIES, Tone Vale Hospital, Norton Fitzwarren, Taunton, Somerset TA4 IDB

Sir: We are grateful to Dr Davies for his comments on our paper. While his views may appear somewhat alarmist, we would agree that in the present political climate doctors are vulnerable to being scapegoated when their patients behave dangerously. The newly introduced Supervision Register is a prime example of this. To what extent psychiatrists can be held liable for their patients' behaviour is unclear. We believe that 